\title{
OS SENTIDOS DA CULTURA MATERIAL NO COTIDIANO E NA MEMÓRIA DAS FAMÍLIAS DA COMUNIDADE QUILOMBOLA DE CINCO CHAGAS DO MATAPI
}

\author{
The meanings of material culture in daily activities and memory in the Comunidade \\ Quilombola de Cinco Chagas do Matapi families
}

Clarisse Callegari Jacques ${ }^{1}$

\section{RESUMO}

Neste artigo, busco discutir a temática da relação da cultura material com a memória e a oralidade a partir de vivências e experiências que tive até agora na comunidade quilombola do Estado do Amapá, chamada Cinco Chagas do Matapi. Destaco o papel da cultura material como mediadora de relações de alteridade, e a participação e o diálogo como aspectos metodológicos importantes da etnografia que contribuem para a prática de uma arqueologia mais reflexiva. Através de vestígios arqueológicos e de atividades atuais da comunidade, é possível estudar os diferentes sentidos da cultura material, entendida como ativa, e capaz de evocar lembranças e imagens de um passado não distante. É com a oralidade que os sentidos da memória, da paisagem e da cultura material se misturam e constituem a história e a identidade da comunidade de Cinco Chagas do Matapi.

Palavras-chave: cultura material, memória, quilombolas.

\begin{abstract}
In this article I intend to discuss the theme of the relation between material culture, memory and oral speech through daily experiences I've had until now in an african-descendent community in Amapá State (Brasil), called "Cinco Chagas do Matapi". Material culture plays an important role as a mediator in alterity relations, and participation and dialogue are important ethnographic methodologies that contribute to a more reflexive practice of archaeology. From archaeological remains and recent community activities it is possible to study material culture's different meanings, as active and capable of evoquing memories and images of a not distant past. It is through oral speech that the senses of memory, landscape and material culture intermixes and constitutes the history of 'Cinco Chagas do Matapi' community.
\end{abstract}

Key-words: material culture, memory, African-descendants.

\section{RESUMEN}

Este trabajo trata de analizar el tema de la relación de la cultura material de la memoria y la oralidad de las experiencias y vivencias que he tenido hasta ahora en la comunidad de marrón en el estado de Amapá, llamado las Cinco Llagas Matapi. Destacar el papel de la cultura material como mediadora de las relaciones de alteridad, y la participación y el diálogo como los aspectos metodológicos importantes de etnografía que contribuyen a la práctica de la arqueología más reflexiva. A través de actividades arqueológicas y actuales de la comunidad, es posible estudiar los distintos significados de la cultura material, entendida como activa y

\footnotetext{
${ }^{1}$ Doutoranda PPGA/UFPA/CAPES. E-mail: clarissejacques@yahoo.com
} 
capaz de evocar recuerdos e imágenes de un pasado no muy lejos. Es con ese sentido de la memoria oral, el paisaje y la cultura material se mezclan y forman la historia y la identidad de la comunidad de las Cinco Llagas Matapi.

Palabras Clave: cultura material, memoria, cimarrones

\section{Introdução}

A Arqueologia tem se deparado com situações cada vez mais desafiadoras durante seu trabalho de campo. Nos contextos onde os vestígios materiais estão localizados em áreas ocupadas atualmente por comunidades, pequenas vilas e fazendas, dizem respeito não só à vida das pessoas que os produziram e utilizaram no passado, mas possuem significados para diferentes pessoas que entram em contato hoje com esses vestígios.

No caso da pesquisa que venho desenvolvendo ${ }^{2}$ na Comunidade Quilombola de Cinco Chagas do Matapi, Estado do Amapá, foi encontrada pelos membros desta comunidade uma botija de cerâmica enterrada no meio de uma plantação de mandioca. O interesse da comunidade em querer saber mais sobre esta vasilha me instigou a desenvolver uma pesquisa que levasse em conta a relação destas pessoas com os vestígios arqueológicos neste local. Assim, até agora foram realizadas várias visitas à comunidade de Cinco Chagas, sendo que durante uma delas foi escavada esta vasilha a pedido do Instituto do Patrimônio Histórico e Artístico Nacional (IPHAN) através de um projeto de resgate emergencial ${ }^{3}$.

Neste artigo, busco discutir a temática da relação da cultura material com a memória e a oralidade ${ }^{4}$. Neste sentido, parto de vivências que tive até agora na comunidade e destaco que a cultura material teve um papel importante como mediadora de relações de alteridade. Em um primeiro momento discuto uma abordagem teórica acerca dos estudos sobre cultura material, e busco apresentar os vestígios materiais como cultura material ativa, ligada às pessoas e às suas experiências de vida. Em seguida, exploro o potencial da materialidade dos vestígios arqueológicos enquanto evocadores de memórias e histórias a partir de encontros com os moradores de Cinco Chagas. Em um último momento, reflito sobre o papel central da

\footnotetext{
${ }^{2}$ Atualmente, venho desenvolvendo pesquisa de doutorado no Programa de Pós Graduação em Antropologia na Universidade Federal do Pará (PPGA/UFPA/CAPES).

${ }^{3}$ Uma vez identificada a boca desta vasilha na roça de mandioca, o IPHAN, em visita a comunidade, solicitou a realização de um projeto de resgate arqueológico para evitar que este vestígio seguisse sofrendo com as ações do tempo. Assim, foi desenvolvido pelo IPHAN um projeto de resgate pontual desta vasilha no qual atuei como coordenadora responsável tendo em vista meu interesse de realizar pesquisas na área. Os resultados desta atividade foram apresentados em forma de relatório a este órgão (JACQUES, 2011).

${ }^{4}$ As ideias principais deste artigo foram desenvolvidas no trabalho final da disciplina 'Cultura Material' ministrada pela Profa. Dra. Marcia Bezerra no PPGA/UFPA e apresentadas no I Congresso Pan-Amazônico e VII Encontro da Região Norte de História Oral realizado em Belém em 2011.
} 
oralidade na pesquisa, que está me direcionando a lembranças, conhecimentos e fazeres próprios das famílias que vivem nesta comunidade e que, por sua vez, dizem respeito a sua história e ao seu patrimônio. A história da comunidade, presente na memória e contada através da oralidade, se manifesta através da cultura material.

\section{Os vestígios materiais e as experiências de vida das pessoas da Comunidade de Cinco Chagas}

A Comunidade Quilombola de Cinco Chagas do Matapi pertence ao município de Santana, Amapá, e está localizada nas margens do Rio Matapi a 19 quilômetros da cidade de Macapá. Atualmente, a principal atividade das famílias que moram ali é a produção da farinha e sua venda na feira da cidade de Santana, para onde se deslocam periodicamente de barco. A atividade de revolver a terra para plantar e colher a mandioca tem feito com que as pessoas entrem em contato com fragmentos de vasilhas de cerâmica e alguns eventuais instrumentos de pedra polida diariamente. Foi a descoberta de uma botija inteira que chamou atenção, fazendo com que as pessoas entrassem em contato com a Prefeitura de Santana e o IPHAN para preservar esta vasilha e conhecer mais sobre a sua história.

O fato de as pessoas terem interesse neste artefato (na minha visão de arqueóloga) me fez visitar a região com o técnico do IPHAN em outubro de 2009 e começar a pensar em um projeto de arqueologia. Enquanto arqueóloga entendi, naquele momento, aquele lugar como um sítio arqueológico com vestígios materiais de vasilhas cerâmicas indígenas ocupado atualmente por uma comunidade quilombola que está interessada em conhecer mais sobre estes artefatos. Os membros de Cinco Chagas, por sua vez, entendem a botija enterrada como parte da sua história, como uma descoberta que deve ser preservada para que pessoas de outros lugares possam visitar. Ainda, segundo o relato de alguns moradores, outras comunidades do Rio Matapi possuem escolas, postos de saúde e igreja, mas não apresentam uma situação como aquela, de aparecimento de uma botija enterrada no solo. É interessante pensarmos nesta informação contextualizando o momento em que esta comunidade se encontra, tendo optado pelo pedido de reconhecimento da Comunidade de Cinco Chagas como comunidade remanescente de quilombo frente ao Estado.

As comunidades tradicionais, incluindo-se nestas as comunidades quilombolas, enquanto grupos familiares com percepções do mundo próprias, uso comum de recursos e apropriação privada de bens de forma consensual (ALMEIDA, 2004), possuem também um entendimento próprio sobre o seu patrimônio, onde o passado e o presente estão relacionados. 
Neste sentido, o tradicional não se refere somente ao contexto histórico do grupo, mas aos saberes e fazeres atuais. As comunidades possuem especificidades próprias, a ver com a sua história, seu autorreconhecimento e as suas atividades quotidianas. Assim, no caso de Cinco Chagas, além da vasilha enterrada estar associada à história e à identidade das famílias, é um elemento importante enquanto especificidade ou diferencial de legitimidade desta comunidade.

Estas são duas visões, uma visão minha e a outra um entendimento que tive em um primeiro momento sobre uma mesma situação, na primeira saída de campo. Com o tempo, tive a oportunidade de visitá-los outras vezes e me convenci que existem ainda muitas outras versões, visões e entendimentos desta história, deste lugar e desta botija enterrada. Além disso, ainda com um olhar de arqueóloga, percebi que alguns dos fragmentos identificados nas roças visitadas dizem respeito a cacos de vasilhas de grupos quilombola e não só de indígenas, conforme algumas pessoas da comunidade já haviam me chamado a atenção. A riqueza da relação da cultura material com as pessoas, as sensações, interpretações, desejos, esperanças, memórias, fascínio que permeia este contato faz com que, neste projeto, a cultura material seja estudada como agente, como ativa e não somente um produto de uma atividade humana.

Neste sentido, Miller (1987) destaca que frequentemente os artefatos são associados à sua função, o que muitas vezes determina o nome pelo qual são chamados. Pensar somente nesta perspectiva é limitar o entendimento da cultura material; o autor propõe que o crucial é a relação social do objeto com as pessoas. Pensando esta proposta não só para artefatos, mas para coisas em geral, pois nós nos cercamos delas (CSIKSENTMIHALYI, 1993:25), é estudar a forma como as pessoas entendem e se relacionam com o mundo à sua volta (THOMAS, 1996).

Para Tilley (2008), a cultura material pensada em relação à sua materialidade traz a tona uma questão ambígua. Por um lado a matéria é propriedade interessante da cultura material, pois pode proporcionar sensações relacionadas às características como textura, cor e cheiro, que as palavras não conseguem expressar. Por outro lado, a cultura material representa relações sociais e simbolismos que fazem parte do mundo das ideias, e não do material. Sendo assim, o autor propõe o uso do termo objetificação como um conceito que possibilita uma forma de entendimento das relações entre sujeitos e objetos que não são vistos como diferentes; ou seja, as ideias, valores e relações sociais são criadas junto com o processo que faz com que as coisas passem a existir.

A objetificação, assim, é um processo que aproxima as pessoas e as coisas, sendo estabelecidos vínculos como os de identidade e memória, que fazem do objeto também um agente. Neste sentido, de entender os objetos enquanto ativos, Gell (1992) ressalta que os 
efeitos que os objetos de arte provocam nas pessoas são o seu poder, uma mágica que liga o mundo material ao campo das ideias (e sentimentos). Pode-se pensar também em uma comunicação (GLASSIE, 1999), que está presente tanto na criação como no consumo de um artefato.

Falar de objetos que 'encantam', termo usado por GELL (1992: 222), é tocar também no que fascina um arqueólogo. Todavia, prender-se somente em um mundo material, já admirado e analisado pelo pesquisador, é limitar a pesquisa ao sentido da visualidade e ao mundo das coisas. Esta discussão coloca em cena o conceito de 'cultura material', que não é entendido neste trabalho somente como coisas palpáveis, mas também é visto no sentido do próprio conceito de objetificação colocado por Tilley (2008), e pode estar representado por uma paisagem ou uma imagem trazida pela memória de um lugar. É desta forma que proponho pensar a cultura material relacionada à Comunidade Quilombola de Cinco Chagas do Matapi.

Como foi relatado acima, o primeiro objeto que caracterizou este local como sítio arqueológico foi a vasilha inteira, também chamada de "igaçaba" ou "botija". Associadas à esta vasilha estão histórias que remetem ao imaginário e ao passado da comunidade. Vários moradores relataram suas diferentes experiências com esta vasilha. Contaram, por exemplo, da surpresa dela ter sido encontrada em um determinado ponto, e de ter permanecido neste mesmo local. Os relatos sobre como ela foi descoberta sempre são associados a uma história passada de geração para geração, que fala de vasilhas com ouro no seu interior e que aparecem nos sonhos das pessoas em lugares diferentes, desaparecendo em certas circunstâncias para reaparecer em outros locais.

Do ponto de vista arqueológico, após uma escavação emergencial feita a pedido do IPHAN do Amapá (JACQUES, 2011), constatamos que havia outras duas vasilhas de dimensões menores depositadas junto a esta botija maior, encontrada pela comunidade. $\mathrm{O}$ contexto estratigráfico interpretado a partir da escavação indicou a abertura de uma fossa para a deposição destes artefatos. Com a informação de que havia um pequeno pratinho com um pó branco dentro da vasilha maior, e com a descoberta de outros pratos dentro das duas outras vasilhas associadas à principal, interpretei esta deposição como fazendo parte de um contexto funerário associado a uma ocupação indígena ${ }^{5}$. Estes relatos dos moradores locais e as informações da arqueologia contam a história de vida desta vasilha.

\footnotetext{
${ }^{5}$ As características de decoração plástica presentes na superfície das vasilhas cerâmicas escavadas indicam uma semelhança com as características da cerâmica da Fase Mazagão, estudada por Meggers e Evans (1957) e associadas a uma ocupação indígena.
} 
Ao conviver em Cinco Chagas neste período, percebi que ao longo de toda a área onde estão as casas, foram encontrados fragmentos de vasilhas cerâmicas que, uma vez vistos pelas crianças sob a ótica da arqueologia, passaram a encontrá-los ainda mais e a relatar onde se localizavam. O olhar destas crianças, não tão "treinado" (ou poderia dizer "direcionado" ao que eu já conhecia em publicações sobre o tema) quanto o meu, me fez perceber outros fragmentos com características um pouco diferentes das que eu estava acostumada, e que me remeteram às decorações e formatos das "louças" de cerâmica feitas atualmente pela Comunidade Quilombola do Maruanum e expostas para venda na Casa do Artesão em Macapá.

Tive a oportunidade de visitar esta outra comunidade, localizada no Rio Maruanum (braço do Rio Matapi) em outro momento, o que me remeteu novamente a um olhar científico arqueológico (com o natural encanto pelos artefatos) preocupado em diferenciar as características dos fragmentos associados a grupos indígenas pretéritos comparando-os com os já vistos em coleções e publicações de arqueologia, das características da "louça" quilombola ${ }^{6}$. As pessoas de Cinco Chagas com quem conversei sobre o assunto, contam de uma época em que eram compradas vasilhas no Maruanum para guardar água e torrar café, e quando questionei sobre o que achavam dessas diferenças de coloração e decoração nos fragmentos, algumas opinaram que certas vasilhas eram muito antigas, feitas por índios.

Adentrar uma discussão sobre a associação destes fragmentos a uma identidade quilombola ou indígena não é o objetivo neste momento, visto que é uma questão delicada e nada simples. $\mathrm{O}$ interessante, para esta pesquisa, é perceber como está sendo a relação das pessoas com estes fragmentos e levar em consideração também que a visão da comunidade (e a minha também) tem mudado conforme nos encontramos e ainda poderá mudar. Até agora foi possível constatar que a vasilha inteira é muito importante para essas pessoas, mas não pode ser entendida como o único patrimônio material. Como eles mesmos chamaram a atenção desde o início, a produção de farinha é uma atividade que envolve saberes, técnicas e instrumentos de trabalho também ricos em memória e identidade.

Dentro da abordagem aqui proposta para entender os vestígios arqueológicos presentes nesta comunidade e a forma como as pessoas se relacionam com eles, a memória tem um papel importante. É ela que, muitas vezes, reporta as pessoas ao passado, traz à tona imagens e lembranças, confortos e saudades de momentos que são recriados e reinterpretados através da narrativa oral.

\footnotetext{
${ }^{6}$ Trabalho nada fácil ao qual este projeto não está dedicado.
} 


\section{Memórias e histórias na Casa de Farinha}

Dentre muitos objetos e objetificações relacionadas à vida diária das famílias de Cinco Chagas, e pensados enquanto cultura material ativa, gostaria de destacar os relacionados à atividade de produção de farinha, que dizem respeito desde os cacos de cerâmica e pés de mandioca até os raspadores de mandioca, forno, farinha e outros objetos utilitários e da memória. Cada núcleo familiar planta a mandioca nas suas terras, sendo que pode haver pessoas que vêm de fora e passam um período trabalhando a partir de um acordo com o proprietário. As áreas plantadas estão tanto junto das casas, que por sua vez se localizam ao longo da margem do rio Matapi, como também podem estar mais afastadas. Enquanto em uma parte do terreno são plantadas as mudas, em outra é revolvida a terra e em uma terceira é feita a colheita de mandioca, de forma que essa seja produzida ao longo de todo o ano. A partir da lida e da intimidade com a terra através da plantação, um dos moradores mais antigos da comunidade me indicou as fronteiras das roças onde param de aparecer fragmentos de cerâmica e de terra mais escura, indicativos para o arqueólogo de locais antigamente ocupados.

Todas as famílias usam a Casa de Farinha, inclusive ao mesmo tempo, em um processo contínuo que envolve descascar, deixar de molho, ralar, tirar o tucupi e a goma ${ }^{7}$, espremer a massa, torrar a massa e, ao mesmo tempo, deixar sentar a goma e ferver o tucupi. Enquanto uns estão descascando, outros lidam com outra etapa da produção ao ralar e, ao mesmo tempo, outra família já está no final do processo de torrar e ferver o tucupi.

A dinâmica da casa de farinha envolve a circulação de corpos e coisas, como se fosse uma dança onde os corpos se movem sem se tocar, as crianças vêm e vão, ajudando em alguns processos, as mulheres descascando, lavando a mandioca e fervendo o tucupi, e os homens descascando, torrando, ralando e carregando as sacas de massa da mandioca ralada em um processo harmonioso. Para espremer a massa da mandioca, a comunidade construiu uma prensa de madeira que acelera o processo antes feito com o tipiti ${ }^{8}$. Cada um possui uma preferência de instrumento usado para descascar, seja uma faca menor, maior ou um raspador de metal próprio para isso e argumentam sobre qual é o mais prático e eficiente. As sacas com

\footnotetext{
${ }^{7} \mathrm{O}$ tucupi e a goma são resultados do processamento da mandioca brava. Depois de descascada e de ficar de molho, a mandioca é ralada e "lavada" com água. Deste líquido sai o tucupi e a goma, o primeiro é fervido e temperado, e a goma é usada para fazer tapioca.

${ }^{8}$ Estrutura cilíndrica feita de trançado de fibra de talo da palmeira do buriti para espremer a massa da mandioca, separando o líquido da massa, que será torrada posteriormente.
} 
a farinha pronta são amontoadas em um canto, parecendo todas iguais aos meus olhos, mas pertencem a produções familiares diferentes.

Pensando um pouco nestas sensações e percepções que envolvem esta atividade de produção, destaco as ideias de Spence (2007), que propõe a percepção multisensorial para mostrar como os diferentes sentidos influenciam a percepção do tato. Ao dar-se conta da substância dos objetos, são usados outros sentidos, ou seja, como propõe o autor, nem tudo que acontece em contato com a superfície da pele tem a ver com o toque. O descascar a mandioca implica em consistências de pedaços da mandioca ainda com casca indicadas pelo olhar, mas retiradas com golpes de intensidades diferentes para deixar a raiz livre de reentrâncias de ramificações. No processo de lavagem, ao mexer a massa ralada com água é possível sentir concentrações diferentes e definir a quantidade de tucupi que vai estar presente em cada produção de farinha; pois isso vai mudar o seu gosto. Na torragem, a cor, o deslizar da pá no forno, a granulometria na farinha - às vezes peneirada para ficar mais fina - e provar o ponto certo são percepções essenciais.

Enquanto visitante frequente, converso com as pessoas que me explicam o processo e me deixam a par das suas vidas e ficam, ao mesmo tempo, a par da minha. Ao transitar na Casa de Farinha, me deparo com áreas mais quentes, onde é fervido o tucupi e torrada a mandioca, e passo pela fumaça do forno e o vapor da mandioca sendo torrada para chegar onde a água lava a massa e o suco escorre para recipientes onde a goma vai sentar. São cheiros diferentes em cada processo, e o aroma do tucupi fervido com alho e alfavaca predomina na Casa de Farinha, objetificando todo este processo e todos os saberes nele envolvidos.

Estas impressões e experiências que tive em campo me levam a pensar no potencial da cultura material enquanto mediadora da relação entre pesquisador e interlocutor. Através dela, a participação e o diálogo também acontecem. A participação acontece no sentido de compartilhamento, no qual o trabalho de campo refere-se a um mundo que compartilhamos com outras pessoas e com outros olhares e sensibilidades, mas com uma mesma convivência (LIMA e SARRÓ, 2006:20). O diálogo é uma relação de alteridade que compartilha o mesmo tempo (FABIAN, 2002) e que implica em uma troca de saberes através da cultura material. Para Carlos R. Brandão (2007) a pesquisa é uma vivência, uma relação interpessoal e de subjetividade, e o envolvimento pessoal e o contexto da pesquisa são dados que fazem parte da prática de campo.

A mandioca, em suas diferentes versões, seguindo o gosto de cada um, retoma diferentes significados e relaciona a história do lugar com a biografia particular de cada 
pessoa, assim como associa os fragmentos cerâmicos ao cotidiano da comunidade. Retomando as ideias de Gosden (2005), as coisas de origens e históricos diferentes se juntam para formar um modo de vida com ocorrência e lógica. Na minha ideia inicial, mandioca e fragmentos de cerâmica nada tinham em comum; com o tempo, se tornaram parte de uma mesma história.

No meio da cultura material e das histórias, estão as memórias. Estas memórias dizem respeito tanto ao indivíduo como ao coletivo, referindo-se, respectivamente, como ressalta Pollak (1992: 2), aos acontecimentos vividos pessoalmente e os vividos pelo grupo ao qual a pessoa sente pertencer. A primeira não pode ser dissociada da segunda, pois, como coloca Bosi (2004:54), ao refletir sobre os estudos de Halbwachs, a memória do indivíduo está relacionada ao da sua família e com outros contextos nos quais está presente um coletivo como, por exemplo, a Igreja, o trabalho, a escola, que são os grupos de convívio e de referência do sujeito.

As diferentes formas de fazer farinha, de perceber a cultura material à sua volta nos remetem a uma história pessoal cheia de detalhes e experiências do indivíduo. Cada um com uma história de vida, cada um se inserindo nas histórias e nas práticas do grupo a partir das suas memórias particulares. Ao mesmo tempo, essas memórias são "herdadas", como sugere Pollak (1992: 4), e vêm de um contexto compartilhado com outros sujeitos. A ligação entre o indivíduo e o coletivo é intensa e frequente, e pude perceber isso, principalmente, nos relatos sobre os diferentes entendimentos sobre a presença da "igaçaba" ou "botija" enterrada na roça da comunidade. O local onde ela apareceu é importante, mas o que parece ser crucial é a pessoa que a encontra, para quem a botija apareceu em sonho. A forma como me contaram que ela apareceu, como ela foi procurada por esta pessoa e os fenômenos associados ao ponto onde ela se encontrava como ruídos de passos e luzes fortes à noite, variam.

A memória, neste sentido, é entendida como uma construção (POLLAK, 1992; BOSI, 2004) que tem a ver com a percepção das pessoas sobre as histórias contadas, suas interpretações e experiências com a cultura material. Ulpiano Menezes (1998), em publicação intitulada "Memória e Cultura Material: Documentos Pessoais no Espaço Público" refere-se ao papel da cultura material nos processos de rememoração ainda sendo abordado pelos pesquisadores de forma tímida o que tende a ser ainda uma prática se tomarmos como importante a influência dos mesmos nas vidas das pessoas. A história do aparecimento da botija é um exemplo: mostra que as relações das pessoas com a cultura material são múltiplas e ricas, suscetíveis a novas interpretações e repassadas através da oralidade. 
A Casa de Farinha enquanto cultura material possui suas representações. Seus materiais construtivos, como o telhado feito manualmente com a sobreposição de galhos com folhas longas envolvem também saberes específicos. A origem destes materiais de construção e o destino do produto da Casa de Farinha, bem como a circulação de coisas e pessoas, me remete à ideia de Gonçalves (2007) de que acompanhar o deslocamento dos materiais é entender a dinâmica social. Um dos objetivos dessa comunidade é reformar a Casa de Farinha, considerada "feia" por muitos; precisa ser reformado seu telhado e seu piso, principalmente. Dentre muitos outros, é patrimônio deste local. Como coloca Gosden (2005), devemos olhar a genealogia dos objetos e também as práticas que eles encorajam e permitem. Seguindo esta perspectiva, as pessoas e a cultura material estão entrelaçadas e são entendidas sempre uma em relação à outra.

Enquanto figura na paisagem, possui destaque como um lugar importante economicamente falando, um lugar para ser mostrado aos que vêm de fora, um lugar de reuniões e um lugar de convívio diário. Para Thomas (1996), a existência humana implica em estar em algum lugar (ideia que o autor desenvolve a partir do pensamento de Heidegger); este autor discute paisagem, corpo e lugar na arqueologia. A percepção do espaço perpassa a experiência do corpo, a noção de distância, por exemplo, é orientada no mundo de acordo com a maneira que as pessoas entendem o corpo e o que faz parte dele varia de sociedade para sociedade. Falar de espaços e lugares implica também em refletir sobre a visualidade enquanto cultura material. Não se trata de uma casa de farinha qualquer, é um lugar com objetos que fazem sentido para aquelas pessoas, que contam sobre a sua história, que suscitam encontros e estimulam histórias contadas através da oralidade. A prensa foi feita na comunidade e substitui o tipiti, que somente uma pessoa sabe fazer e que vende, às vezes, para outras comunidades. O ato de descascar mandioca tem a ver com o de contar histórias; assim como os momentos de silêncio na casa de farinha direcionam as pessoas aos seus pensamentos e às suas lembranças pessoais.

Os vestígios arqueológicos, como cultura material ativa, estão relacionados com a mandioca e objetificam atividades diárias das famílias como o plantio, a colheita e a convivência na casa de farinha. São diversos tipos de cultura material que criam memórias; os cacos agora também lembram a arqueóloga "pesquisadora”, que aparece ocasionalmente e que anda pela área tirando fotos. 


\section{A oralidade remete a paisagens e a memórias criadas}

Ao pensar corpo e espaço e a constituição de paisagens, não podemos deixar de considerar a memória. O corpo enquanto veículo que, estando em um lugar (THOMAS, 1996), permite ao ser humano sentir, ver e mais tarde lembrar através da construção de uma imagem na mente de uma situação, de um lugar. Para Pollak (1992) esses "lugares da memória" estão ligados à lembrança. Esta imagem que vem à mente, criada pela pessoa que viveu uma experiência, pode ser também entendida como cultura material.

Pensando a visualidade como fator importante para se entender a cultura material, gostaria de retomar outras experiências que tive em campo e que, refletindo agora, me instigou a pensar a paisagem e a imagem enquanto cultura material. Como visitei a comunidade em momentos diferentes do ano, na época da chuva e na época da seca, uma das pessoas com quem tive maior contato sempre brincou comigo apresentando o terreno como "limpo" na época da seca, pois a vegetação não cresce tanto, e "sujo" no inverno (época de chuva), fazendo com que as pessoas andem somente nas trilhas de uma casa para outra. No inverno, "tudo fica sujo, com mato", e dá mais trabalho para as pessoas, que têm que "roçar" na volta das casas com maior frequência. São duas paisagens diferentes, e estas paisagens estão relacionadas a uma estética e ao próprio corpo que circula neste espaço.

Além disso, nestes momentos diferentes, os objetos que compõe a paisagem variam, algumas coisas ficam visíveis e outras não, ou umas menos e outras mais. Na época da chuva, a superfície fica mais encoberta, mais difícil também para visualizar os fragmentos de cerâmica. $\mathrm{Na}$ época em que a vasilha ainda não havia sido escavada, a família proprietária do terreno ficava mais descansada na época de chuva, pois a área onde a vasilha se encontrava ficava mais 'suja' e, assim, chamava menos atenção e não corria tanto o risco de pessoas desavisadas irem mexer.

Neste sentido, se pensarmos em patrimônio relacionado à ideia de herança - no sentido de cuidar, valorizar e transmitir - e construção, pois é um termo criado a partir do nosso olhar (JORGE, 2000: 125), o termo objetificação é um conceito interessante para se pensar os vestígios arqueológicos, os objetos ligados ao cotidiano da comunidade e a imagem de lugares. Estes, ao mesmo tempo, referem-se à história, à memória e à experiência social dos núcleos familiares que constituem a comunidade. Isso, por sua vez, indica a necessidade de problematizarmos o conceito de patrimônio arqueológico, que se torna mais amplo e que inclui as noções próprias da comunidade sobre o que é importante para eles. Neste sentido, a 
arqueologia colabora buscando a construção conjunta do conhecimento e do patrimônio dos lugares através de práticas de pesquisa participativas.

Um lugar que apareceu durante as conversas com os moradores da comunidade de Cinco Chagas foi o "lugar dos antigos", onde a primeira família ocupou a região, em uma área mais distante das margens do rio Matapi. Tive a oportunidade de visitar este local, onde uma das moradoras da comunidade me acompanhou com seu filho. Foi difícil identificar a trilha para chegar lá, segundo ela, apesar de ser muito perto das outras casas. Isso aconteceu porque o mato já havia tomado conta, o que sempre acontece em época de chuvas. Neste local não há roça. Aos meus olhos, ao visitar o local, vi uma mata com árvores frutíferas e terreno disforme, e me perdi facilmente na orientação do espaço.

Conforme caminhávamos no terreno, a moradora da comunidade procurava na paisagem atual os lugares da sua memória (POLLAK, 1992), sempre acompanhada de seu filho. Seguindo ela, tentei imaginar como poderia ter sido este lugar, como era a casa, como era a roça, como era o lugar de torrar farinha... De repente ela chama atenção para uma bacabeira ${ }^{9}$, e em um ponto inclinado do terreno encontra na sua lembrança a antiga casa. A partir deste momento ela segue fazendo a leitura daquela paisagem através de uma volta no tempo (considerando esta lembrança também como uma construção, como chama a atenção ROCHA e ECKERT, 2000), às suas memórias e, ao mesmo tempo em que nos conta onde costumava ficar cada coisa, relata para seu filho como era o seu bisavô, e de como ela costumava cuidar dele. Identificamos o antigo poço, encontramos alguns restos da antiga estrutura de madeira da casa e ela chamou a atenção à quantidade de coisas que ainda deveriam estar aparecendo ali naquele lugar, se o mato não tivesse avançado. Ao mesmo tempo em que se lembra dos momentos, explica como era a vida naquela época, e se emociona retomando sentimentos pessoais; o filho, quieto, escuta pacientemente. Já determinados a voltar para casa, nos deparamos com os restos do antigo forno feito com latas emendadas, onde era torrado o café e a farinha. Ela pede que eu tire uma foto do filho segurando este objeto, orgulhosa de mostrar para ele como vivia seu bisavô. Terminamos a visita colhendo uma jaca madura, que seria apreciada juntamente com as lembranças do lugar.

Miller (1987) coloca que existe uma relação próxima entre a materialidade do objeto e a materialidade do espaço, sendo que os objetos podem se referir a relações sociais e, neste caso, também ao passado. Com certeza a imagem que eu via e que ela via eram diferentes, a dela uma paisagem da memória, e a minha uma tentativa de transformar o que eu estava

\footnotetext{
${ }^{9}$ Palmeira com fruto a partir do qual é tirado vinho e que é muito consumido pelas comunidades ribeirinhas no Amapá e na Amazônia.
} 
vendo e o que estava sendo narrado em uma cena à minha frente. Conforme caminhávamos neste espaço, as árvores e os vestígios iam puxando a lembrança de situações do passado, iam retomando a história da comunidade, iam ressignificando a paisagem. Entendendo a memória como "espaço de construção de conhecimento" (ECKERT e ROCHA, 2000: 2), é ver o passado não “(...) necessariamente antagônico ao presente, ao contrário, eles superpõem-se ritmicamente e, num processo ondulatório, ao ponto da sua consolidação, deixam a descoberto a matéria de suas lembranças” (ROCHA e ECKERT, 2000: 13).

A partir das experiências que vivi até agora em Cinco Chagas do Matapi, percebi a possibilidade da história ser contada através de narrativas orais tendo os lugares, os momentos e os objetos papéis de contextos que desencadeiam a memória. Em especial, uma vez que pesquiso a relação dos vestígios arqueológicos com as pessoas nesta comunidade, a cultura material evoca e cria memória, imagens, momentos passados, sentimentos. As coisas que nos cercam possuem a capacidade de sintetizar uma história através do seu poder de evocar a memória e instigar a narrativa.

\section{Considerações finais}

Uma pesquisa que leve em consideração abordagens metodológicas como a participação, a dialogia e a problematização sobre a relação de alteridade são perspectivas do campo da antropologia que podem auxiliar o arqueólogo a desenvolver uma prática de pesquisa mais reflexiva e ética (SMITH, 2004; SHANKS e HODDER, 1998). Além disso, a cultura material, enquanto mediadora de relações sociais, apresenta um potencial enorme enquanto abordagem teórica e metodológica para problematizar a alteridade.

Os vestígios arqueológicos, enquanto parte do patrimônio de Cinco Chagas, estão relacionados com a sua luta pelo reconhecimento enquanto comunidade quilombola. As narrativas, através de imagens da memória das famílias, estão vinculadas a um sentimento de pertencimento e associam as experiências e identidades sociais manifestas a um território (MARIN e CASTRO, 1999: 76). Imbricadas nas demandas por melhorias sociais e reconhecimento frente ao Estado estão as relações estabelecidas pelas pessoas com a história particular das comunidades e com a materialidade.

Os arqueólogos, em suas pesquisas de campo, têm muito a aprender com a oralidade, que mostra alguns sentidos da cultura material; esta, por sua vez, diz respeito às pessoas hoje, e não só a um passado distante. Ainda, os artefatos e vestígios, associados a outros objetos e imagens, remetem a uma identidade própria das pessoas do local, que tem a ver com os seus 
saberes e fazeres, suas casas, suas histórias e suas visões de mundo. Desta forma, não é mais possível ir a campo e não escutar as pessoas, e não deixar a oralidade nos levar para diferentes lugares através das imagens e nos mostrar diferentes perspectivas da cultura material.

\section{Referências bibliográficas}

ALMEIDA, Alfredo W. B. de. "Terras tradicionalmente ocupadas: processos de territorialização, movimentos sociais e uso comum" In: Revista Brasileira de Estudos Urbanos e Regionais, v.6, n. 1, p. 9-32, 2004.

BOSI, Ecléa. Memória e sociedade, lembranças de velhos. São Paulo: Companhia das letras, 2004.

BRANDÃO, C. R. "Reflexões sobre como fazer trabalho de campo" In: Sociedade $e$ Cultura,v.10 n. 1, p. 11-27, 2007.

CSIKSENTNIHALYI, Mihaly. "Why we need things". In: LUBAR, Steven e KINGERY, David. W. (eds.) History from things. Essays on material culture. p. 20-29. Washington and London: Smithsonian Institution Press, 1993.

ECKERT, Cornelia.; ROCHA, Ana. L. "Os jogos da memória” In: Iluminuras, Porto Alegre, v. $1, \quad$ n. 2, p. 2-15, 2000 . Disponível online em: http://seer.ufrgs.br/iluminuras/article/view/9108.

FABIAN, J. Time and the other. How anthropology makes its object. [1983]. New York: Columbia Univ. Press, 2002.

GELL, Alfred. "The Technology of Enchantment and the Enchantment of Technology". In: COOTE, Jeremy e SHELTON, Anthony. (eds.) Anthropology, Art and Aesthetics. p. 40-63. Oxford: Clarendon Press, 1992.

GLASSIE, Henry. Material culture. Indianapolis: Indiana University Press, 1999.

GONÇALVES, Reginaldo. Antropologia dos objetos: coleções, museus e patrimônios. Rio de Janeiro: Editora Garamond, 2007.

GOSDEN, Chris. "What do objects want?" In: Journal of Archaeological Method and Theory, v. 12, n. 3, p. 193-211, 2005.

JACQUES, Clarisse C. Relatório de Atividades do Projeto: Resgate Emergencial Arqueológico na Comunidade Quilombola de Cinco Chagas do Matapi, AP. IPHAN, agosto de 2011, datiloscrito.

JORGE, V. O. "Por uma concepção abrangente e dinâmica do patrimônio arqueológico: algumas ideias para um debate" In: Arqueologia, património e cultura. Lisboa: Instituto Piaget, 2000. 
LIMA, Antónia P. de; SARRÓ, Ramon. "Introdução. Já dizia Malinowski: sobre as condições da possibilidade da produção etnográfica" In: LIMA, Antónia Pedroso de; SARRÓ, Ramon (orgs.). Terrenos Metropolitanos-ensaios sobre produção etnográfica. Lisboa: ICS, 2006.

MARIN, Rosa. A.; CASTRO Edna. R. "Mobilização Política de Comunidades Negras Rurais: Domínios de um conhecimento praxiológico" In: Novos Cadernos NAEA, v. 2, n. 2, dezembro, 1999.

MEGGERS, B. J.; EVANS, C. "Archaeological Investigations at the Mouth of the Amazon. Smithsonian Institution" In: Bureau of American Ethnology, Bulletin 167. Washington: Government Printing Office, 1957.

MENEZES, Ulpiano B. "Memória e cultura material: documentos pessoais no espaço público" In: Estudos Históricos, v. 11, n. 21, p. 89-104, 1998.

MILLER, Daniel. Material culture and mass consumption. Oxford: Blackwell, 1987.

POLLAK, Michael. "Memória e identidade social" In: Estudos Históricos, Rio de Janeiro, vol. 5, n. 10, p. 200-212, 1992.

ROCHA, Ana. L.; ECKERT, Cornelia. "Imagens do tempo nos meandros da memória: por uma etnografia da duração" In: Iluminuras, Porto Alegre, v. 1, n. 1, p. 2-14, 2000. Disponível online em: http://seer.ufrgs.br/iluminuras/article/view/8928/5157.

SHANKS, Michael.; HODDER, Ian. "Processual, postprocessual and interpretative archaeologies" In: WITHLEY, D (ed.). Reader in Archaeological Theory: post-processual and cognitive approaches. p. 69-95. London: Routledge, 1998.

SMITH, Linda. "Archaeolological theory and "the Politics of the Past" In: Archaeological Theory and the politics of Cultural Heritage. London: Routledge, 2004.

SPENCE, Charles. "Making sense of touch: a multisensory approach to the perception of objects" In: PYE, Elizabeth (ed.) Touch: handling objects in museum and heritage contexts. Walnut Creek: Left Coast Press, 2007.

THOMAS, Julien. Time, culture and identity. An interpretative archaeology. London \& New York: Routledge, 1996.

TILLEY, Christopher. "Objetification" In: TILLEY, Christopher; KEANE, Webb; KÜCHLER, Susanne; ROWLANDS, Mike e SPYER, Patricia. (eds) Handbook of material culture. New York: Sage, 2008. 